\title{
Stress and Coping Strategies among Premedical and Undergraduate Basic Science Medical Students in a Caribbean Medical School
}

\author{
Shankar PR, Balasubramanium R, Ramireddy R, Diamante P, Barton B, Dwivedi NR
}

Xavier University School of Medicine, Aruba, Kingdom of the Netherlands

\begin{tabular}{ll}
\hline ARTICLE INFO \\
Received & $: 15 / 07 / 2014$ \\
Accepted & $: 16 / 10 / 2014$ \\
Published & $: 01 / 12 / 2014$
\end{tabular}

KEYWORD

Brief COPE

Caribbean

Coping strategies

Medical students

Student stress

\section{ABSTRACT}

Introduction: Sources of stress and coping strategies have not been previously studied at Xavier University School of Medicine, Aruba. Objective: Hence the present study was carried out to obtain information about sources of stress and coping strategies among different groups of students and note differences, if any, among subgroups of respondents. Method: Sources of student stress and coping strategies were studied using the medical student stressor questionnaire (MSSQ) and the brief COPE. The present study was carried out among premedical and basic science undergraduate medical students during June 2014. Demographic characteristics like gender, semester of study, age and nationality were noted. Mean scores of different groups of stressors and coping strategies were calculated and compared among various subgroups of respondents using appropriate statistical tests $(\mathrm{p}<0.05)$. Result: Ninety-two of the 108 students (85.2\%) participated. Cronbach's alpha values for various categories of stressor scores were high. The major categories of stressors were academic related and group activity related. Certain stress scores were higher among female respondents and undergraduate medical (MD) students especially those studying in the fourth and fifth semester. The main coping strategies employed were planning, active coping, positive reframing, and acceptance. There were differences in use of certain coping strategies among subgroups of respondents.Conclusion: Academic related stressors were high especially among fourth and fifth semester students. Longitudinal studies following students over their basic science years are required. Studies among students doing their clinical rotations in the United States are required. Studies among students in other Caribbean medical schools are needed.

(C) Medical Education Department, School of Medical Sciences, Universiti Sains Malaysia. All rights reserved.

CORRESPONDING AUTHOR: Dr P Ravi Shankar, Xavier University School of Medicine, Aruba.

Email:ravi.dr.shankar@gmail.com

\section{Introduction}

Medical students face a variety of situations which cause stress in both their personal and academic life. Previous studies have found high levels of stress among medical students (1-4).
Higher rates of depression and anxiety have also been noted among female medical students compared to age matched peers in the general population (5). Too much stress can cause physical and mental health problems, reduce students' self-esteem and can affect their 
academic performance (6). Stress among medical students has been classified into academic issues, social problems and financial difficulties. Society has high expectations from medical students who are expected to learn and master a large amount of information and skills. They have to make personal and social sacrifices to do well in a competitive environment which places them under a lot of stress.

Stressors among medical students have been divided into academic related stressors (ARS), intrapersonal and interpersonal related stressors (IRS), teaching and learning-related stressors (TLRS), social related stressors (SRS), drive and desire related stressors (DRS), and group activities related stressors (GARS) (7). Studies have shown that the top four stressors among medical students were tests and examinations, time pressure, too much course content and getting behind in work (7-9). Conflicting demands, not getting work completed in time and heavy workload have also been commonly reported.

Stress has been mentioned as the body's nonspecific response or reaction to demands made on it or to disturbing events in the environment. The Medical Student Stressor Questionnaire (MSSQ) was developed to study stress among medical students and has good internal validity and reliability as shown in a recent study (10). Studies among medical students in different Malaysian medical schools had shown that MSSQ had good validity and reliability $(11,12)$. The original MSSQ had 40 items but recently the six factor model with 20 items was shown to be a good fit and to have good psychometric properties (11).

Handling a stressful situation or a stressor is dependent on how persons cope with it. Two major types of coping efforts, problem-focused and emotion-focused have been distinguished $(13,14)$. Carver and co-workers had originally identified fifteen dimensions of coping among which five assessed various types of problemfocused coping e.g. active coping, planning, suppression of competing activities, restraint coping and seeking instrumental social support, five assessed emotion-focused coping e.g. seeking emotional social support, positive reinterpretation, acceptance, denial, turning to religion while the last five assessed responses that may be less useful like venting, behavioural disengagement, self-distraction, humour and substance use (13). The original COPE had 60 items with 15 coping dimensions but in 1997 Carver proposed a shorter version of the COPE termed as the brief COPE which consisted of 14 scales with each scale having two items (14). The brief COPE has been widely used to study coping strategies among various groups of students including medical students $(15,16)$.

Coping strategies have been divided into active and avoidant coping strategies (17). Active coping is considered a better way to deal with stress while avoidant coping is considered as a risk factor for adverse responses to stressful life events (18). The various coping strategies have been grouped together into three main ones which are problem-focused, active emotional and avoidant emotional (19). Problem-focused coping includes active coping, planning, instrumental support, and religion while active emotional coping includes venting, positive reframing, humour, acceptance and emotional support. Avoidant emotional coping consist of self-distraction, denial, behavioural disengagement, self-blame and substance use.

Xavier University School of Medicine (XUSOM) is a private medical school in Aruba admitting students from the United States (US), Canada and other countries to the undergraduate medical (MD) course (20). The school also runs a premedical program to prepare students who have completed high school for admission to the MD program. In January 2013 the school shifted to an integrated curriculum and problem-based learning (PBL) sessions, and medical humanities, early clinical exposure, use of standardized patients for both teaching and assessment, family health visits, sessions on critical appraisal of scientific literature (CASL) have been introduced for MD students. An online module on patient safety and healthcare 
quality improvement provided by the Institute for Healthcare Improvement (IHI) is also offered to all MD students. Initially the normal human subjects (anatomy, physiology and biochemistry) were taught during the first two semesters while the abnormal subjects of pathology, microbiology, pharmacology and introduction to clinical medicines were taught over the third and fourth semester. However from January 2014 all basic science subjects are taught in an integrated, organ system-based manner with early clinical exposure (21). Sources of stress and coping strategies have not previously been studied in the institution. Hence the present study was conducted to study sources of stress and coping strategies among premedical and undergraduate medical students during the basic science years of the course and note differences in sources of stress and coping strategies adopted according to demographic characteristics of respondents, if any.

\section{Method}

The present study was carried out among premedical and basic science undergraduate medical students at the Xavier University School of Medicine, Aruba during the month of June 2014. Students were informed about the study and invited to participate. Written informed consent was obtained from all participants. The study was approved by the Institutional Review Board of XUSOM vide notification XUSOM/IRB/2014/03.

Demographic characteristics like gender, semester of study, age and nationality were noted. Sources of student stress were studied using the short version of the Medical Student Stressor Questionnaire (MSSQ) developed by Yusoff (11). Respondents were asked to rate a set of twenty items or stressors using a scale of 0 to 4 . The scoring system used was as follows: 0 = causing no stress at all, 1 = causing mild stress, 2 = causing moderate stress, 3 = causing high stress and $4=$ causing severe stress. The stressors were divided into six groups: academic related stressors (ARS), intrapersonal and interpersonal stressors (IRS), teaching and learning related stressors (TLRS), social related stressors (SRS), drive and desire related stressors (DRS), and group activity related stressors (GARS). The mean and standard deviation scores of different groups of stressors were calculated. The mean scores among different subgroups of respondents were compared using appropriate statistical tests. Independent samples t-test was used for dichotomous variables and analysis of variance (ANOVA) for others. A p value of less than 0.05 was considered as statistically significant.

Coping strategies employed by respondents to deal with sources of stress was studied using the brief COPE. A set of 28 coping strategies was listed. For each strategy respondents were asked how much or how frequently they were using the particular strategy. The scale used was as follows: 1 = I haven't been doing this at all, 2 = I've been doing this a little bit, $3=$ I've been doing this a medium amount and $4=$ I've been doing this a lot. The statements were grouped together into various coping strategies. Among the strategies employed were self-distraction, active coping, denial, substance use, use of emotional support, use of instrumental support, behavioural disengagement, venting, positive reframing, planning, humour, acceptance, religion and self-blame. The mean \pm SD scores of various coping strategies were calculated and compared among various subgroups of respondents using appropriate tests $(\mathrm{p}<0.05)$. The coping strategies were also grouped together into problem-focused, active emotional and avoidant emotional as mentioned in the introduction (19).

Free text comments from respondents were invited and tabulated.

\section{Result}

A total of ninety-two of the 108 students (85.2\%) participated in the study. Table 1 shows the demographic characteristics of the respondents. Not all respondents filled in all demographic characteristics in the questionnaire. 
Table 1: Demographic characteristics of student respondents

\begin{tabular}{lc}
\hline Characteristic & Frequency (\%) ${ }^{*}$ \\
\hline Gender & $47(51.1)$ \\
Male & $34(37.0)$ \\
Female & \\
Semester of study & $21(22.8)$ \\
Premed & $10(10.9)$ \\
MD 1 & $13(14.1)$ \\
MD 2 & $18(19.6)$ \\
MD 3 & $13(14.1)$ \\
MD 4 & $17(18.5)$ \\
MD 5 & \\
Nationality & $33(35.9)$ \\
American & $16(17.4)$ \\
Canadian & $18(19.6)$ \\
Others & $15(16.3)$ \\
Age in years & $36(39.1)$ \\
Less than 20 & $22(23.9)$ \\
20-25 & \\
Greater than 25
\end{tabular}

* The numbers may not add up to 92 as some respondents did not provide information on certain demographic characteristics

Cronbach's alpha value was calculated for the six groups of stressors. For ARS the value was 0.874 while for IRS the score was 0.927 . The value for TLRS was 0.830 while for SRS the value was 0.780 . For DRS and GARS the values were 0.777 and 0.814 . The overall value was 0.915 .

The mean \pm SD ARS score was $2.89 \pm 0.86$. The mean \pm SD GARS and SRS scores were $2.01 \pm$ 0.96 and $1.71 \pm 1.02$. The mean \pm SD IRS, DRS and TLRS scores were $1.36 \pm 1.28,1.09 \pm 1.25$ and $1.46 \pm 1.13$. The maximum possible score in each category was 4 .

Table 2 shows stressor values which were significantly different among groups of respondents. GARS and IRS scores were higher among female respondents. Other stress scores were also higher among females compared to males though the difference was not statistically significant. Many stress scores were also higher among undergraduate medical (MD) students compared to premedical respondents. Stress scores were higher among the fourth and fifth semester MD respondents.

Table 2: Stressor values which were significantly different among subgroups of respondents

\begin{tabular}{|c|c|c|c|}
\hline Stressor & $\begin{array}{c}\text { Respondent } \\
\text { Characteristic }\end{array}$ & $\begin{array}{l}\text { Mean } \\
\text { value }\end{array}$ & p-value \\
\hline \multirow[t]{3}{*}{ GARS } & Gender & & 0.023 \\
\hline & Male & 1.88 & \\
\hline & Female & 2.29 & \\
\hline \multirow[t]{3}{*}{ IRS } & Gender & & 0.015 \\
\hline & Male & 1.12 & \\
\hline & Female & 1.86 & \\
\hline \multirow[t]{3}{*}{ ARS } & Course of study & & 0.003 \\
\hline & Premed & 2.24 & \\
\hline & MD & 3.08 & \\
\hline \multirow[t]{3}{*}{ SRS } & Course of study & & 0.038 \\
\hline & Premed & 1.26 & \\
\hline & MD & 1.83 & \\
\hline \multirow[t]{10}{*}{ ARS } & Semester of study & & 0.004 \\
\hline & PM1 & 2.02 & \\
\hline & PM2 & 2.04 & \\
\hline & PM3 & 2.30 & \\
\hline & PM4 & 2.20 & \\
\hline & MD1 & 3.02 & \\
\hline & MD2 & 3.25 & \\
\hline & MD3 & 2.89 & \\
\hline & MD4 & 3.03 & \\
\hline & MD5 & 3.25 & \\
\hline \multirow[t]{10}{*}{ SRS } & Semester of study & & 0.004 \\
\hline & PM1 & 0.87 & \\
\hline & PM2 & 0.86 & \\
\hline & PM3 & 1.39 & \\
\hline & PM4 & 0.94 & \\
\hline & MD1 & 0.93 & \\
\hline & MD2 & 2.23 & \\
\hline & MD3 & 1.70 & \\
\hline & MD4 & 1.90 & \\
\hline & MD5 & 2.16 & \\
\hline
\end{tabular}

With regard to coping strategies the mean selfdistraction, active coping and denial scores were 4.93, 5.68 and 2.65. The mean scores for substance abuse, emotional support and instrumental support were 2.27, 4.14 and 4.62. The scores for disengagement, venting, positive reframing and planning were 2.81, 3.58, 5.09 and 5.84 while the mean scores for humour, acceptance, religion and self blame were 3.64 , 4.96, 4.68 and 4.88. 
Table 3 shows the coping strategies employed which were significantly different among groups of respondents. Male respondents used humour as a coping strategy more than females. Emotional support and instrumental support as coping strategies were used more by MD students compared to premed. The coping strategies were grouped into three strategies as mentioned in the introduction (19). The mean \pm SD scores for problem focused coping, active emotional coping and avoidance coping were $20.83 \pm 5.17,21.40 \pm 5.47$ and $17.55 \pm 4.42$. There was no significant difference in the type of coping strategies used among different groups of respondents.

Among the free text comments were:

"Something which has really worked for me in coping with stress is going to the gym and eating healthy. I highly recommend this to new students.” (MD4 respondent)

"I have little or no stress.” (Another respondent)

A MD2 respondent stated, "Sports activities help with stress.”

A respondent mentioned that verbal abuse from classmates has occurred during the last few weeks while another mentioned gaming as a stress reliever.

A MD3 respondent mentioned, "Basically the stress I feel is not absolutely school related. It has more to do with life as a whole. Learning how to deal with people. Two important things which give me stress are financial worries including school fees and not being able to manage my time so as to study effectively."
Table 3: Coping strategies which were significantly different among subgroups of respondents

\begin{tabular}{|c|c|c|c|}
\hline $\begin{array}{l}\text { Coping } \\
\text { strategy }\end{array}$ & $\begin{array}{c}\text { Respondent } \\
\text { Characteristic }\end{array}$ & $\begin{array}{l}\text { Mean } \\
\text { value }\end{array}$ & $\begin{array}{c}\text { p- } \\
\text { value }\end{array}$ \\
\hline \multirow[t]{3}{*}{ Humour } & Gender & & 0.001 \\
\hline & Male & 4.21 & \\
\hline & Female & 3.05 & \\
\hline \multirow{3}{*}{$\begin{array}{l}\text { Emotional } \\
\text { support }\end{array}$} & Course of study & & 0.011 \\
\hline & Premed & 3.43 & \\
\hline & MD & 4.35 & \\
\hline \multirow{3}{*}{$\begin{array}{l}\text { Instrumental } \\
\text { support }\end{array}$} & Course of study & & 0.013 \\
\hline & Premed & 3.90 & \\
\hline & MD & 4.83 & \\
\hline \multirow[t]{3}{*}{ Planning } & Course of study & & 0.040 \\
\hline & Premed & 5.24 & \\
\hline & $\mathrm{MD}$ & 6.01 & \\
\hline \multirow{10}{*}{$\begin{array}{l}\text { Self- } \\
\text { distraction }\end{array}$} & Semester of study & & 0.012 \\
\hline & PM1 & 5.10 & \\
\hline & PM2 & 6.20 & \\
\hline & PM3 & 4.31 & \\
\hline & PM4 & 4.01 & \\
\hline & MD1 & 4.00 & \\
\hline & MD2 & 4.92 & \\
\hline & MD3 & 4.40 & \\
\hline & MD4 & 5.54 & \\
\hline & MD5 & 5.76 & \\
\hline \multirow{10}{*}{$\begin{array}{l}\text { Emotional } \\
\text { support }\end{array}$} & Semester of study & & 0.029 \\
\hline & PM1 & 3.00 & \\
\hline & PM2 & 2.99 & \\
\hline & PM3 & 3.56 & \\
\hline & PM4 & 3.21 & \\
\hline & MD1 & 4.90 & \\
\hline & MD2 & 4.77 & \\
\hline & MD3 & 3.39 & \\
\hline & MD4 & 4.69 & \\
\hline & MD5 & 4.47 & \\
\hline \multirow{10}{*}{$\begin{array}{l}\text { Instrumental } \\
\text { support }\end{array}$} & Semester of study & & 0.029 \\
\hline & PM1 & 3.38 & \\
\hline & PM2 & 3.40 & \\
\hline & PM3 & 4.06 & \\
\hline & PM4 & 4.10 & \\
\hline & MD1 & 5.80 & \\
\hline & MD2 & 5.23 & \\
\hline & MD3 & 3.67 & \\
\hline & MD4 & 4.69 & \\
\hline & MD5 & 5.29 & \\
\hline
\end{tabular}




\section{Discussion}

The major sources of stress among respondents in our study were academic related stressors (ARS) and group activity related stressors (GARS). The mean score for these two categories could be ranked as high (mean score between 2.01 and 3.00) while the scores for the other groups of stressors could be classified as moderate (mean score between 1.01 and 2.00) (22). The coping strategies mainly used were self-distraction, active coping, emotional support, instrumental support, positive reframing and planning. Respondents mainly used active emotional and problem focused coping. There were differences in the sources of stress and coping strategies according to certain demographic characteristics of respondents.

The Cronbach's alpha values for different groups of stressors in the study were high. The values were comparable to those obtained by Yusoff in his study (10). In a multicenter study on the validity of the MSSQ, the overall Cronbach's alpha value was found to be 0.95 while all stressor groups showed a value greater than 0.7 (12). In another study the Cronbach's alpha value of the MSSQ was 0.92 and the values of six constructs were more than 0.7 as in the present study (11). The present study again confirms the reliability of the MSSQ in a different student population.

ARS was high in our study which was similar to that observed in a study in Nepal where the common sources of stress were staying in a hostel, high parental expectations, vastness of syllabus, tests and exams, lack of time and paucity of entertainment facilities (3). Academic stressors were also high in a study conducted among dental students at the University of the West Indies though the predominant stressor varied according to the year of study (23). In our study prevalence of GARS and IRS was significantly higher among female students. ARS scores were also higher among females but the difference was not significant. With increasing number of PBL and small group activity-based sessions interpersonal skills become important though we are not able to explain why this should cause more stress among female respondents. In a study conducted in the United Arab Emirates, frequency of examinations, time management, and academic workload were identified as the main stressors by both first and second year students (4).

Previous studies have used various instruments to assess sources of stress among medical students. In Pokhara, Nepal a 29 item list of potential stressors was developed by the authors and respondents identified academic stressors as the most important (3). Authors in the UAE developed a 22 item questionnaire to identify stress among students $(4,24)$. Frequency of exams, academic workload and time management were the major sources of academic stress. In our study most stressors were higher among MD students compared to premedical ones. The stress levels were particularly high among MD5 students who were preparing for the United States Medical Licensing Exam (USMLE) step 1.

The main coping strategies used by students were self-distraction, active coping, positive reframing, planning, and acceptance. In the UAE multiple coping strategies were adopted by students including praying, planning and learning from the experience (4). Students mainly used problem focused and active emotional coping like in previous studies. Emotional and instrumental supports were used more by MD students compared to premed respondents which are opposite to that observed in the UAE study (4). In Nepal students mainly used active coping strategies and positive reframing, acceptance, planning, active coping, self-distraction and emotional support (3). The coping strategies were different according to gender and year of study. In our study also male respondents used humour more while planning was used more by MD students. In a Turkish study, active coping styles were used more frequently by male students, and students with a higher family income (25). In a study among medical students in Nigeria, use of religion, 
planning, acceptance, use of instrumental support, denial were commonly used (15).

Substance abuse scored low as a coping strategy which is similar to the results of previous studies. In Nepal the mean score for substance abuse was 2.50 (3) which were higher than the 2.27 reported in our study. A similar finding was noted in the UAE study (4) and among students in Nigeria the mean score was 1.4 which is lower than that reported in our study (15). However, reports from the US and Canada have reported much higher use of substances with up to $20 \%$ of students reporting the same (26).

PBL strategies may result in new sources of stress among medical students who have to shift from a predominantly teacher-centred to a student-centred learning approach, and have to deal with the pressure of performing in small group situations and uncertainty about the content to be mastered (27). Authors have suggested that PBL curricula should provide more social support by peers and faculty and a more supportive learning environment and as medical schools modify their curricula the psychological impact should be monitored to prevent an increase in stress and depression (27, 28). At XUSOM the main teaching-learning strategy employed continues to be didactic lectures and support systems for students including faculty mentoring, academic counselling and a peer tutoring program are in place.

ARS and GARS scores at the institution were high while other scores were moderate. The main coping strategies employed were planning, active coping, positive reframing, and acceptance. As mentioned students have different support systems in the school ranging from each student having a faculty mentor, a trained clinical psychologist and the academic enhancement program where senior students provide academic help to junior students who wish to avail of the service. MD5 students have a separate course director who provides them one to one support and counselling. This should be further strengthened. Students on the island are away from their home and family and we are working towards letting students know what is expected from them during the course and the competencies they are expected to achieve at the end of a particular course of study. Scholarships and private student loan programs are available for students in need and the school also offers students the option of paying their tuition fee in instalments. We are happy to note that substance abuse as a coping strategy was low.

The strength of the study was the high response rate. Sources of stress and coping strategies were studied using two validated instruments. However psychological morbidity among students was not studied. MSSQ is a new instrument and has not been validated among varied student populations. A detailed qualitative study to identify sources of student stress and coping strategies was not carried out. The accuracy of the study depends on the truthfulness of student responses.

\section{Conclusion}

Academic related stressors were high among students especially among fourth and fifth semester undergraduate medical students. Group activity related stressors were also high. Stress levels were higher among female respondents and active coping strategies were more widely employed. Longitudinal studies following students over their basic science years are required. With changes in the curriculum and greater emphasis on self-directed learning and group work it may be important to study student stress levels and coping strategies as the integrated curriculum gets more established. Studies among students in the clinical years doing their clinical rotations in the United States are required. Studies among students in other Caribbean medical schools are needed.

\section{Acknowledgement}

The authors acknowledge the help of Dr Muhamad Saiful Bahri Yusoff for giving them permission to use the MSSQ for this study. They acknowledge all students who participated in the study. 


\section{Reference}

1. Al-Dubai SA, Al-Naggar RA, Alshagga MA, Rampal KG. Stress and coping strategies of students in a medical faculty in Malaysia. Malays J Med Sci. 2011;18:5764.

2. Dahlin M, Joneborg N, Runeson B. Stress and depression among medical students: A cross-sectional study. Med Educ. 2005;39:594-604. doi:10.1111/j.13652929.2005.02176.x

3. Sreeramareddy CT, Shankar PR, Binu VS, Mukhopadhyay C, Ray B, Menezes RG. Psychological morbidity, sources of stress an d coping strategies among undergraduate me dic-al students of Nepal. BMC Med Educ. 2007;7:26. doi:10.1186/1472-6920-726

4. Gomathi KG, Ahmed S, Sreedharan J. Causes of stress and coping strategies adopte $\mathrm{d}$ by undergraduate health professions studen ts in a university in the United Arab Emirates. Sultan Qaboos Univ Med J. 2013;13:437-41.

5. Dyrbye LN, Thomas MR, Shanafelt TD. Systematic review of depression, anxiety, and other indicators of psychological distress among US and Canadian medical students. Acad Med. 2006;81:354-73.

6. Niemi PM, Vainiomaki PT. Medical students' academic distress, coping and achievement strategies during the preclinical years. Teach Learn Med. 1999;11:125-34.

7. Yusoff MSB, Rahim AFA, Yaacob MJ. The development and validity of the Medical Student Stressor Questionnaire (MSSQ). ASEAN Journal of Psychiatry 2010;11(1):13-24. Available online: http://www.aseanjournalofpsychiatry.org/ind ex.php/aseanjournalofpsychiatry/article/view File/49/40

8. Saipanish, R. Stress among medical students in a Thai medical school. Med Teach. 2003:25;502-506.

9. Aktekin M., Karaman T., Senol Y.Y., Erdem S., Erengin H. \& Akaydin M. Anxiety, depression and stressful life events among medical students: a prospective study in Antalya, Turkey. Med Educ. 2001; 35: 1217.

10. Yusoff MSB. The stability of MSSQ to measure stressors among medical students.
International Medical Journal 2013;20 (2):13.

11. Yusoff MSB. A Confirmatory Factor Analysis Study on the Medical Student Stressor Questionnaire among Malaysian medical students. Educ Med J. 2011;3(1): e44-e53. doi: 10.5959/eimj.3.1.2011.or5.

12. Yusoff MSB. A multicenter study on validity of the Medical Student Stressor Questionnaire (MSSQ). International Medical Journal 2011;18(1):14-18.

13. Carver CS, Scheier MF, Weintraub JK. Assessing coping strategies: a theoretically based approach, J Pers Soc Psychol 1989;56:257-283.

14. Carver CS. You want to measure coping but your protocol too long: consider the Brief COPE. Int J Behav Med 1997; 4(1): 92-100.

15. Yussuf AD, Issa BA, Ajiboye PO, Buhari OI. The correlates of stress, coping styles and psychiatric morbidity in the first year of medical education at a Nigerian University. Afr J Psychiatry (Johannesbg). 2013;16:206-15. doi: http://dx.doi.org/10.4314/ajpsy.v16i3.28.

16. Cherkil S, Gardens SJ, Soman DK. Coping styles and its association with sources of stress in undergraduate medical students. Indian J Psychol Med. 2013;35:389-93. doi: 10.4103/0253-7176.122235.

17. Krohne HW. Vigilance and cognitive avoidance as concepts in coping research. In: Krohne HW, editor. Attention and avoidance: Strategies in coping with aversiveness. Seattle (WA): Hogrefe \& Huber Publishers; 1993. p. 19-50 .

18. Schnider KR, Elhai JD. Coping style use predicts posttraumatic stress and complicated grief symptom severity among college students reporting a traumatic loss. J Couns Psychol. 2007;54:344-50.

19. Holahan CJ, Moos R H. Risk, resistance, and psychological distress: A longitudinal analysis with adults and children. J Abnorm Psychol. 1987;96(1):3-13.

20. Shankar P, Dubey AK. 'Modernizing' the Basic Sciences MD program at XUSOM, Aruba. WebmedCentral Medical Education 2013;4(4):WMC004198.

21. Shankar PR, Bharti R, Ramireddy R, Balasubramanium R, Nuguri V. Students' perception of the learning environment at Xavier University School of Medicine, Aruba: a follow up study. J Educ Eval Health Prof 2014, 11:9. http://dx.doi.org/10.3352/jeehp.2014.11.9 
22. Yusoff MSB, Rahim AFA. The medical student stressor questionnaire (MSSQ) manual. 2010. Available from: https://www.researchgate.net/publication/20 0640404_The_Medical_Student_Stressor_Q uestionnaire_\%28MSSQ\%29_Manual

23. Naidu RS, Adams JS, Simeon D, Persad S. Sources of Stress and Psychological Disturbance among Dental Students in the West Indies. J Dent Educ. 2002;66:1021-30.

24. Gomathi KG, Ahmed S, Sreedharan J. Psychological health of first-year health professional students in a medical university in the United Arab Emirates. Sultan Qaboos Univ Med J. 2012;12:206-13.

25. Kaya M, Genç M, Kaya B, Pehlivan E. Prevalence of depressive symptoms, ways of coping, and related factors among medical school and health services higher education students. Turk Psikiyatri Derg. 2007;18(2):137-46.

26. Dyrbye LN, Thomas MR, Shanafelt TD. Systematic review of depression, anxiety, and other indicators of psychological distress among US and Canadian medical students. Acad Med 2006;81:354-73.

27. Lewis AD, Menezes DA, McDermott HE, Hibbert LJ, Brennan SL, Ross EE, Jones LA. A comparison of courserelated stressors in undergraduate problembased learning (PBL) versus non-

PBLmedical programmes. BMC Med Educ. 2009;9: 60. doi: 10.1186/1472-69209-60.

28. Moffat KJ, McConnachie A Ross S, Morrison JM. First-year medical student stress and coping in a problem-based learning medical curriculum. Med Educ. 2004; 38:482-491. doi:10.1046/j.13652929.2004.01814.X 